\title{
Commentary Essay
}

\section{Threat Assessment in the Post-Columbine Public School System: The Use of Crisis Management Plans in the Public School Sector as a Means to Address and Mitigate School Gun Violence}

Received (in revised form): March 19, 2007

\section{Crystal Lee Collins}

International Journal of Educational Advancement (2007) 7, 46-61. doi:10.1057/palgrave.ijea.2150043

Over the last several years, the use of public relations and crisis management practices has proliferated into areas of American culture far removed from the business world in which it previously solely resided. Along with nonprofit organizations concerned with their social responsibility and higher education institutions attempting to win the student recruitment arms race, public elementary, middle, and secondary schools have begun more aggressively to research and utilize several principles of public relations in

Author's Contact Address:

Crystal Collins

Southern Regional Education Board

592 10th Street NW

Atlanta

Georgia 30318 5776, USA

E-mail: crystal.collins@sreb.org

Tel: 4048795538 their daily work. Along with edification about image restoration and dealing with activist publics, public school administrators have turned to the public relations field as a resource for best practices when instituting crisis management plans-which address such disparate events as ways to protect students during a severe weather event to evacuation of all personnel during an on-campus hostage situation. In the wake of September 11th and Hurricane Katrina, many school districts reviewed their crisis preparedness plans, instituting changes based on new threats or mistakes made by other institutions suffering through these overwhelming events. These evaluation procedures mimicked the severe reflection sought by school officials after the deadliest years for school 
violence that ended with the massacre of 12 students and one teacher at Columbine High School in 1999. This area of public school crisis management response has been especially impacted by the infiltration of for-profit sector external relations, relying on business practices to update the precrisis, crisis, and postcrisis measures followed during an act of on-campus gun violence.

During the 1990s, 28 instances of targeted violence occurred in America's public school systems, culminating with the largest mass homicide in history at that time on April 20, 1999 , at Columbine High School in Littleton, Colorado (Omoike, 2000; Vossekuil et al., 2002). In the wake of this horrific attack, states and school districts across the nation revisited their outdated crisis management plans, turning to corporate public relations research to inform changes in the mostly reactive characteristics of gun violence prevention, investigating strategic and anticipatory models of crisis intervention. On the collective recommendations of the Department of Education, the United States Secret Service, and the Department of Justice, school administrators began to train themselves and their personnel in threat assessment techniques in hopes to prevent their school from becoming the next Columbine (Vossekuil et al., 2002). While the emergency preparedness plans activated postColumbine have decreased the number of student-on-student violent incidences precipitously, inherent shortcomings in these measures have appeared in the last several months with attacks in Colorado, Wisconsin, and Pennsylvania by adults in no way associated with their eventual victims. Perhaps the time has come for public school administrators to revisit the crisis management research to address these new assailants and safety concerns. In an attempt to chart a new course for secondary schools' gun violence crisis preparation, one must understand the history of homicide at these institutions.

Ask any American to name the three largest mass murders in United States history and the first two should come easily to mind (e.g. the attacks of September 11, 2001 in New York City and the bombing of the Alfred P. Murrah Federal Building in Oklahoma City, Oklahoma on April 19, 1995). The third, however, may surprise. In 1927, 43 people, including 38 children, perished when a disgruntled former school board member rigged explosives intended to decimate an elementary school in Bath, Michigan (Mohandie, 2002). Andrew Kehoe, a 50-year-old local farmer, spent many months wiring dynamite throughout the basement of the school without encountering a bit of resistance from teachers or administrators (Mohandie, 2002). He succeeded in scarring the small town of Bath almost instantly. This earliest case of mass homicide on campus presents clues to the threads that connect incidences of violence in schools through the devastation of Columbine and Virginia Tech. Similar to Dylan Klebold and Eric Harris, the assassins of Columbine High School, and Cho Seung-Hui at Virginia Tech, Andrew Kehoe informed others of his dissatisfaction with the establishment, yet, just as with the two boys, no one headed his warnings of exacting revenge (Mohandie, 2002). Many viewed Kehoe's actions as an anomaly in an otherwise safe environment, which did not warrant a proactive plan to prevent future occurrences, 
a perception that continued relatively unchallenged through more than 65 years of public school education. The horrific-and perhaps largely preventable-events at Columbine High School in 1999 demanded a change in the mostly reactionary responses previously utilized by school administrators to address school violence.

The most famous school shooting in American history, until recently-the assault on Columbine High School by Dylan Klebold and Eric Harris-took more than a year to plan (Omoike, 2000). The pair placed two 20 pound bombs in the cafeteria on the morning of the 20th of April hoping to massacre most of the 400 students eating lunch inside (Clabaugh and Clabaugh, 2005). When the explosives failed to detonate, Klebold and Harris entered the school armed with several automatic and semi-automatic weapons, and began to indiscriminately shoot students. When the assault ended five hours later, 12 students, one teacher, and both Klebold and Harris lay dead, while some 24 other students suffered life-threatening wounds (Trump, 1999; Clabaugh and Clabaugh, 2005). Later, investigators learned that Klebold and Harris complained of a "cult of the athlete" at the suburban high school, with a "coterie of favored jocks" consistently bullying, hazing, and sexually harassing classmates while receiving special treatment from both school authorities and local law enforcement (Clabaugh and Clabaugh, 2005). Embroiled in this milieu, Klebold and Harris endured constant taunts and slurs as social outcasts from popular students. Administrators knew of this taunting directed at the socalled "trench coat mafia" of which
Klebold and Harris belonged, yet did nothing to mitigate the bullying or alleviate the depression and despair obviously taking over both boys. Realizing that school administrators and teachers seemed unconcerned with their plight, Klebold and Harris chose to assuage their pain in an unhealthy and destructive manner.

Dylan Klebold and Eric Harris embody several of the key findings from Kris Mohandie's investigation into school violence in 2002. Of the three sources of violence identified by Mohandie (2002), Klebold and Harris exemplify the perpetrators of the "most frequent type of lethal and nonlethal [school violence] event that occurs"-a service recipient or "customer" of the school. Mohandie further investigates the reasons behind the proliferation of such peer-based gun violence in the 1990s. Of greatest concern, the proliferation of firearms in America allows for easy access to weapons of mass murder for hurting and hormonal high school students (Mohandie, 2002). The United States possesses a higher rate of firearm deaths than all other 26 industrialized nations combined. Further, weapon availability greatly increases the likelihood of a gun-related homicide or suicide event in adolescence (Mohandie, 2002). The increased presence of weapons on-campus in the late 1990s remains irrefutable, with Department of Education statistics reflecting almost 6,000 students expelled during the 1996-1997 school year under the zero-tolerance weapons ban intended to curtail the presence of firearms on school grounds (US Department of Education, 1999). Klebold and Harris both coveted their gun collections, relying on their easy 
access to so many weapons to aid them in their plot against their fellow Columbine students.

Mohandie (2002) next derides the effects of the media, chastising journalists for sensationalizing stories about school violence and further claims that exposure to violent video games, television, and motion pictures contribute to the violent fantasies possessed by student attackers. Of greatest concern to Mohandie, this media influence most directly affects possible attackers by offering permission for copycat killers. Reliant on media saturation in the coverage of school shootings, this "copycat contagion" results in a "cluster effect" of subsequent violent acts, as in 1999 when Columbine represented only one of six gruesome events that yearincluding two more high school shootings within six months (Omoike, 2000; Vossekuil et al., 2002). Although Klebold and Harris claimed not to be copycat assailants (going so far as to address the shooting in Paducah, Kentucky in 1997, in their video journals later discovered by the police), their involvement with violent video games and fantasy worlds were not in question, causing some to speculate that the cool nature of their assault was rooted in their belief that it was all just a game (Omoike, 2000). Finally, developmental characteristics may account for why teenagers remain the most likely perpetrators of lethal and nonlethal school violence (Mohandie, 2002). According to developmental theorists, teenagers frequently decide to act impulsively without regard for long-term consequences. Developmental psychologists postulate that adolescents actively search for their place in the world at this stage of development and succumb to rejection easily. The taunting experienced by Klebold and Harris symbolized the futility of their attempts to fit in to the culture at Columbine High School.

Hypersensitive to this rejection, the boys chose to inflict physical pain on others in an attempt to bring attention to their own. The disconnect between school personnel mediation and student needs resulted in one of the bloodiest days in American public school history, but it also illuminated a latent problem hidden within institutional emergency preparedness plans.

The break down of communication between students and school personnel, which plagued Columbine High School, represents a crucial deterrent to proactive and preventive measures against student violence. As Americans again sat transfixed to their television screens, watching the horror unfurl in Littleton, Colorado, a call to arms ensued. Buoyed by the formation of a summit on school safety and violence prevention by the then President Bill Clinton on May 10, 1999, school districts across the nation initiated active investigations into means to prevent similar tragic events from happening in their schools in the future (Trump, 1999). Disheartened by the ineffectiveness of previous preventive measures (with the most recent federal recommendations at that time released in August 1998), administrators widened their sphere of influence to include crisis management techniques utilized by big business. Rooted in crisis preparedness and communication research, federal agencies and state government officials developed a national plan of action 
intended to mitigate all types of violence in public schools across the nation. This practical guide for school safety-released in 2003-introduced teachers, students, and administrators to the subject of "threat assessment" as preventive for "targeted violence" (Brickman et al., 2004). An investigation of this public relations research illuminates its influence on current operational crisis management plans in over 30 states, including Colorado, the home of past and present attacks.

In order to understand current crisis preparedness plans in place in hundreds of school districts across the country, one must investigate public relations and crisis communication research and discern the theoretical influence. While the idea of public relations as a tool for public secondary schools may seem superfluous, the heart of public relations can be wielded as a shield against violence on campus. Public relations represents a process intended to mitigate harm directed toward the organization and its constituents, respond to the needs of stakeholders, and repair an institution's image following a crisis (Seeger et al., 2001). Crisis communication, a component of public relations, has undergone a transformation of its own in recent years, with the development of several theoretically grounded models and a broadening of utility beyond simple postcrisis exchanges so as to construct a comprehensive approach to crisis mitigation and preparedness plans (Seeger et al., 2001). As asserted by Seeger and his colleagues in 1998, organizational crises represent "specific unexpected and non-routine events or series of events that create high levels of uncertainty and threaten or are perceived to threaten an organization's high priority goals" (Seeger et al., 2001, p. 156). This previous idea of crisis as an event to be completely avoided diminished with the image management research of the late 1980 s and early 1990s, in which the benefit of a crisis as a "natural phase of an organization's development" developed (Seeger et al., 2001, p. 156). Through the use of proper communication and planning in a proactive manner, an organization may mitigate the negative effects of these natural developmental events, effectively shaping a crisis during its three stages-an incubation or precrisis stage leading to an acute/ crisis stage and ending with the postcrisis or postmortem phase-into an opportunity for growth rather than a threat to the institution (Penrose, 2000; Seeger et al., 2001).

Organizations attempting to lessen harm done by crises must actively participate in environment scanning. This type of crisis communication requires that an institution be cognizant of both interior and exterior environments, interacting with both internal and external actors in order to understand relevant attitudes and public perceptions directed at the institution (Seeger et al., 2001). Such interaction allows an institution to recognize possible threats before they mature, diffusing an event similar to Columbine by identifying trigger events-which may include bullying and harassment-before the crisis erupts. Along with environment scanning, an institution should conduct risk communication among its important constituents. In this activity, organizations must encourage an open and transparent exchange 
of information about the "nature, significance, or control of a risk" (p. 157) with its internal and external parties (Seeger et al., 2001). Risk communication informs all three stages of a crisis. During the precrisis stage, in which prevention and preparation inform the activities pursued, communication illuminates perceptions held by constituent publics concerning the affect of a given risk on the organization, influencing how rigorously an institution prepares for a given crisis (Seeger et al., 2001; Brickman et al., 2004). During the acute stage of a crisis, proper risk communication allows for timely information dissemination resulting in mitigated harm to the organization. Finally, risk communication utilized during the recovery phase crystallizes risk perception into new norms and practices for future precautions (Seeger et al., 2001). As experienced in the business world, schools must manage both genuine and spurious risks. While the risks facing schools cannot be quantified with certainty, the proper application of risk management by an institution results in appropriate precrisis perceptions of norms and elicits positive responses from stakeholders (e.g. students, parents, teachers, and administrators) in the event that a crisis occurs (Seeger et al., 2001). According to Seeger and his colleagues, "inadequate pre-crisis communication increases the probability that a crisis event will be surprising, that precautions will be inadequate, and that serious harm will occur" within an institution (p. 158). As a means to alleviate this issue, an organization must investigate, develop, and institute a crisis management plan.
Preparation for a crisis constitutes the most important tenet of crisis communication and management (Seeger et al., 2001). An institution able to identify and address potential crises will succeed in mitigating harm done by those events. An underlying assumption of this assertion relies on the inherent predictability of many types of crises. This level of prognostication allows an institution to design basic structural plans of crisis management for several potential crises, allowing for more resources when unforeseen events eventually occur (Seeger et al., 2001). Crisis planning allows an organization to approach a predicament with tactics already in place, lessening the stress often associated with an emergency situation. According to Seeger et al., the creation of a crisis management plan generally involves three equally important phases. First, an organization must devise a crisis management team-a structure devised to coordinate disparate crisis management and emergency response expertise within the organization and, often times, from external, but involved, publics. Within the business world, these crisis management teams include the chief executive officer, public relations officer, a designated crisis spokesperson, and representatives from legal, operations, security, and others of appropriate skills (Seeger et al., 2001). These individuals must meet regularly, not only to maintain an updated response plan with recently identified potential crises, but also to develop a rapport between members as a prelude to crisis occurrence, alleviating unfamiliarity when a concerning event transpires. Most important to the success of a crisis 
management team, its members must utilize a team response when addressing any issues (Penrose, 2000). The more individual the response, the less likely success will follow. The preparation level of a crisis response team determines the ability of an organization to deal effectively with a crisis, allowing an institution to return to normal business practices more quickly (Seeger et al., 2001).

The heart of crisis management planning involves the formulation of checklists, decision guides, procedures to mitigate harm to the institution, and prepackaged responses available for immediate release to the press and other external publics in the event of an emergency. Checklists and decision guides represent a popular precrisis tool that place scripted behaviors in an ordered format, allowing an individual to simply progress through predetermined guidelines when faced with a given event. This crisis plan component also often encompasses contact lists for important external constituents, including media outlets and district headquarters (Seeger et al., 2001). When dealing with the media, it behooves an organization to have prepared responses available for immediate release in response to an unfolding event. These predetermined packets should include the history of the organization, the logistics of its product, the history of any preventive measures in place to prevent the occurring crisis, as well as pertinent safety records (Seeger et al., 2001). The presence of these prepared documents decreases uncertainty and boosts the institution's ability to respond promptly to the needs of its various publics, including the media. The maintenance of crisis management plans constitutes the final concern for emergency preparation and represents the most-often ignored aspect of crisis plan formation. While failure of an organization to withstand a crisis often transpires due to the sheer lack of an active crisis management plan, more often than not a deteriorated plan reflects the actual culprit of poor response. Often, businesses that progress and grow without facing emergencies neglect their crisis management plans, allowing these tools to slip into obsolescence. A deteriorated management plan may represent more of a limitation to an organization's ability to withstand a crisis than no plan at all as it symbolizes a false sense of security in the midst of an acute event. Effective public relations and crisis management rely on openness to new information, constant vigilance in the search for possible threats to organizational operation, multiple contingencies in response to these identified concerns, and the possession of a regularly updated, assessed, revised, and practiced crisis management plan (Seeger et al., 2001). A useful tool in the development of such an updated crisis management plan, Burnett's (1998) "crisis classification matrix" allows an organization to systematically identify potential threats to its survival, a key for successful preemptive planning.

John Burnett (1998) discussed the importance of a strategic approach to managing crisis through the application of a brainstorming process characterized as a "vulnerability audit." During this identification stage, an organization employs a 16-cell matrix to identify and label possible crises in the environment (Penrose, 
2000). The four characteristics that differentiate a crisis from a routine strategic decision as defined by Burnett (1998) include threat-level (defined as high or low), response-options (presenting few or many), time pressure (intense or minimal amounts), and degree of control (with the organization possessing high or low amounts of control). The most challenging crises, labeled "level four" emergencies, present intense time pressure, a very low level of institutional control joined with a high threat-level and few available responseoptions (Burnett, 1998). Events which present challenges in two or three of the four characteristics also exemplify crises in need of attention. A problem placed in a "level one" or "level zero" cell (those which exhibit only one or none of the potential confounding characteristics, respectively) lack crisis status and, therefore, do not require a response (Burnett, 1998). The use of this classification system furnishes an organization with a strategic advantage in the battle to mitigate harmful crisis effects. When utilized as a brainstorming mechanism, this crisis classification system allows an organization to identify exhaustively possible crises in the environment, resulting in a more comprehensive crisis management plan (Penrose, 2000). Further, this "vulnerability audit" empowers an institution to gauge the likelihood that a crisis will occur and, in the event that the crisis comes to fruition, the possible severity of its impact (Burnett, 1998). The increased sensitivity of the organization to potential crises created by the implementation of this strategy strengthens its ability to confront potentially detrimental events when they arise, concluding in an effective crisis response during the confrontation or acute stage.

Once an organization identifies potential crises lurking in the environment using the threat matrix as a guide, administrators must transition the focus of the crisis management plan to formulation of contingency strategies specifically designed for the multitude of possible events previously identified. This next stage, referred to by Burnett (1998) as the confrontation stage, equates to Seeger et al's (2001) acute stage and the response phase of the Department of Education's practical guide for schools and communities (Brickman et al., 2004). An organization's ability to create effective contingency scenarios depends directly on the level of effort made in the threat matrix activity of the identification stage. At this stage, an administrator must follow strategic fundamentals, segmenting the population so as to identify the constituents who require the greatest attention (Burnett, 1998). For instance, a school dealing with an ongoing assault on campus must elevate the needs of those students affected by the assault above others for a finite amount of time. The minimization of harm to the institution and its relevant publics remain of utmost importance during this stage of a crisis. Similar to other models of crisis management, Burnett's reconfiguration stage presents the chosen strategy, guided by the desire to resolve the crisis as quickly as possible, and its constant re-evaluation as the final step in a proper plan process. Burnett asserts that this phase should be viewed as a learning opportunity, a chance for the organization to identify successes 
and failures of the chosen strategy. This recovery/postmortem stage of crisis management requires an organization to relate internally, communicating to employees the ideal application of the plan for future incidences. This deed requires a flexible organizational culture and the effectiveness of the preventative depends on the support of all affected. The fulfillment of a plan often depends heavily on the perception of its success and sensitivity to the ability of the potential crisis to do irreparable damage to the institution.

This interesting affect of perception on crisis management interjects another crucial piece to the creation and success of an emergency preparedness plan. While most scholars agree that organizations that practice proactive crisis management succeed more often in the face of an emergency than those that rely on reactive posturing, the perception of internal and external publics of not only the preparedness of the institution but also the affect of the potential crisis, influences the capability of the organization to survive a damaging event (Penrose, 2000). Every institution has the ability to perceive a crisis as either an opportunity-a growthinducing occurrence, or a threatsomething to be feared and shunned. This perception informs the strategic placement of an organization in the process of crisis management planning, determining a mind-set and perhaps influencing its capacity to survive. In a quantitative investigation into the affect of perception on crisis management planning, Penrose (2000) discovered that viewing a crisis as an opportunity induces an institution to greater proactive crisis planning efforts, an indication of success in the mitigation of harm to an organization. A crisis can afford an organization the opportunity to test their preparedness plan in a real-world context, recognizing and strengthening the areas that work and restructuring those that do not. Organizations that view crises as threats, however, limit their proactive actions, including environment scanning and crisis plan implementation, thus empowering perception to control an institution's willingness to engage in preemptive emergency preparedness activities (Penrose, 2000).

The intangible effects of perception add another dimension to crisis management activities. As Penrose (2000) deftly discusses, the assumption that the mere presence of a "solid crisis plan" guarantees success in the face of an emergency represents an ersatz belief. As an example, Penrose bemoans the tragic missteps at the National Aeronautics and Space Administration (NASA) in the moments, days, and weeks following the Challenger explosion on January 28, 1986. Although NASA maintained a detailed crisis management plan, including innumerable checklists, guidelines, and contingency procedures to institute in case of emergency events, one factor remained unaccounted for-the organization's corporate culture. An organization must recognize the affect its corporate culture places on the success or failure of its emergency preparation (Penrose, 2000). According to Penrose, "a crisis management plan is...of limited use if it does not coincide with an organization's philosophies, values, attitudes, assumptions, and norms" (p. 160). Therefore, an organization 
attempting to update or create its crisis management plan must venture beyond the fundamental methods of emergency preparedness discussed in the crisis management literature, which include plans, teams, and communication guidelines, and account for the affect of its unique organizational culture on appropriate methods for success in the face of a possible threat. As part of organizational culture, the level of decentralization also affects the type and success of a crisis management plan. The greater the autonomy available to lower levels of the organization, the more responsive the organization will be when a crisis occurs (Penrose, 2000). This fact applies not only to media relations but also to the physical initiation of a plan during an emergency situation, including an act of gun violence on a school's campus.

The tragedy perpetrated at Columbine High School in Littleton, Colorado, in 1999 forced federal and state agencies, local school districts, and individual institutions to review closely the plans available for prevention of and reaction to gun violence on campus. The Department of Education enlisted the assistance of the Secret Service and the Department of Justice to create practical guidelines for institutions to follow in the event of a "Columbine-like" situation. In 2003, these agencies, in conjunction with one another, released the model document "Practical Information on Crisis Planning: A Guide for Schools and Communities" (Brickman et al., 2004). This document presented safety planning in four stages: prevention and mitigation, preparedness, response, and recovery. In the prevention and mitigation stage, analogous to Seeger et al's (2001) “pre-crisis" phase, institutions must make safety assessments of their individual buildings and campuses (Brickman et al., 2004). These safety assessments include the coordination of the crisis plan with local law enforcement and parents, as well as an investigation into policies for all potential visitors to a campus-including inane deliveries. At this point, institutions participate in internal environment scanning, identifying potential threats permissible due to the campus's structure. During the preparedness stage, another aspect of the precrisis phase, administrators address communication needs for the campus. Officials develop a chain of command to follow in the event of an emergency. Within this discussion of crisis communication, individuals outside the principal (a school's chief executive officer) attain appointment as second and third in command so as to alleviate confusion and stress during a crisis situation if the principal becomes incapacitated or unavailable (Brickman et al., 2004). The Department of Education also suggests naming a liaison for media and parental inquiries, empowering only these individuals to speak on issues associated with the crisis. Here, administrators set the parameters of their crisis communication plan and establish the members of their crisis management teams, both fundamental steps identified by Seeger et al. (2001).

The response stage, as defined by the Department of Education, encompasses development of a response plan to include establishment of a command center, the drafting of a plan with specific directions and checklists, and the dissemination of 
this plan to the appropriate people (Brickman et al., 2004). Here, administrators participate in the minute logistics involved in different crises situations, including mapping evacuation routes, identifying meeting sites for faculty and students within reasonable proximity to campus, and establishing a perimeter to keep media and parents away until law enforcement secures the area (Brickman et al., 2004). The idea of autonomy discussed by Penrose (2000) figures prominently in this acute phase of crisis response. Rather than requiring teachers to receive instructions from the principal or another administrator once they identify an emergency situation, the decentralization of procedures allows for quick response in the face of imminent peril. Finally, institutions must move into the recovery phase as quickly as possible after a crisis event. Administrators must plan for the aftermath, or postmortem, of a crisis, in which schools return to teaching and learning as soon as possible-a direct reflection of Seeger et al.'s (2001) suggestion to return to business as usual with haste. Lastly, school districts must contract mental health services beforehand for their various publics, including those directly (e.g. students, teachers, first responders) and indirectly (e.g. parents, other family members) involved in the crisis (Brickman et al., 2004). While the practical guide offered by the Department of Education lacks specific recommendations for prevention of gun violence on campus, recent research into threat assessment literature performed by the University of Virginia addresses these shortcomings.
Two months after the Columbine incident, the Federal Bureau of Investigation's National Center for Analysis of Violent Crime sponsored a national conference addressing the rash of shootings perpetrated on school campuses over the preceding decade (Cornell and Williams, 2006). The results of this conference offered school systems an outline for dealing with potential violence on campus, including the identification of common factors among assailants in the 37 different instances investigated and possible solutions for campuses to address future emergencies. While many expected the FBI to continue the promotion of student profiling, the base for previous interventions in established crisis management plans, the agency instead supported the practice of "threat assessment," a more intimate form of potential assailant identification (Brickman et al., 2004; Cornell and Williams, 2006). The crux of the "threat assessment" technique relies on communication between teachers and students in order to create an environment where threats of violence are reported, investigated, addressed, and the contributing factors underlying them receive attention. According to researchers at the University of Virginia, this type of crisis management plan remains largely untried by school administrators and uninvestigated by policy researchers (Cornell and Williams, 2006). The influence of previous public relations and crisis management literature permeates the final threat assessment technique, which represents a proper alternative for school districts desiring to update their current gun violence prevention crisis management plans. 
The Federal Bureau of Investigation excels at profiling potential terrorists and yet, in response to the catastrophe perpetrated at Columbine High School, the FBI asserted the fallibility of instituting this method of detection in the nation's school system. While the agency identified common characteristics among assailantsincluding being victims of bullying bordering on harassment, symptoms of depression often coupled with thoughts of suicide, and an unhealthy fascination with violent media (e.g. video games, movies), it also asserted that too many students enrolled in America's school system fit this profile, thus inadvertently creating a phenomenon known as "overprofiling” (Brickman et al., 2004; Cornell and Williams, 2006). A school relying on profiling might generate an unmanageable list of possible threats, and when overwhelmed by these numbers, might unfortunately choose to do nothing. Identified as the most promising discovery, the FBI also determined that students who perpetrate violence almost always communicate these threats to an outside party before following through, either in the form of complaining to friends or occasionally directly addressing the object of their threat (Brickman et al., 2004; Cornell and Williams, 2006). In fact, investigators found that many potential violent acts were thwarted by administrators who utilized appropriate investigative techniques in response to credible threats before follow through by a student occurred (Cornell and Williams, 2006). In light of these two characteristics (the likelihood of over-profiling and prethreat communication), investigators suggested that institutions focus their precrisis efforts on the identification and investigation of students who pose a threat-those who "engage in behaviors that indicate intent, planning, or preparation for an attack" (p. 12) rather than those who might look a certain way (Department of Justice, 2002). This underlying principle of focusing not on what a student verbalizes but on the intention behind such threats informs the actions of the threat assessment team and the formulation of the threat assessment plan.

Among suggestions for creation of the threat assessment team, the Federal Bureau of Investigation recommends the utilization of an internal group, admonishing institutions from outsourcing or centralizing these imperative positions (Cornell and Williams, 2006). A decentralized team allows for quick response to events on campus and also exploits the inherent personal nature of team members knowing each other and the possible perpetrators. This component of crisis management recommended by the FBI and endorsed by several other federal agencies exploits several underlying characteristics of crisis preparedness models previously discussed. Not only does it extol the importance of communication (among members of the team as well as between team members and students) to prevent crises, this characteristic of the threat assessment team allows for effective environmental scanning by those directly involved in prevention and exploits the inherent features of a school's organizational culture. As presented by Penrose (2000), an organization's culture contributes to the success or failure of its crisis 
management plan and, by proxy, team. An internal threat assessment team recognizes and understands the institution's culture, exploiting its familial nature to the advantage of identifying students of possible concern. Members possess a more nuanced understanding of the school and its issues (Cornell and Williams, 2006). The public school system in America promotes and relies on a culture of caring and understanding among students and teachers. The threat assessment technique recognizes this value and employs it to identify potential concerns before they transpire. Finally, an internalized threat assessment team allows for continual reassessment of the school's preparedness, instrumental to success during the recovery or postmortem phase of crisis planning (Seeger et al., 2001; Brickman et al., 2004; Cornell and Williams, 2006).

In the business world, the chief executive officer controls the crisis management team, including various members who possess expertise in given areas (Seeger et al., 2001). The same components comprise the threat assessment teams endorsed by the FBI for schools. The principal or assistant principal represents the equivalent of the CEO, acting as the main disciplinarian on campus, and thus exemplifies an excellent referral point for threat assessment (Cornell and Williams, 2006). In place of a lawyer, school threat assessment teams should include the school resource officer (SRO), a specialized police officer trained to work in a school setting. The FBI and Secret Service both recommend the inclusion of the SRO or, in the event an institution lacks an assigned SRO, a local law enforcement substitution due to their unique skills in preventive and acute crisis matters (Cornell and Williams, 2006). The next set of members encompasses the various mental health specialists available to school administrators. These individuals, including psychologists, counselors, and social workers, may address intent of threats made by students, playing an instrumental role in the prevention of violent events (Cornell and Williams, 2006). While the FBI excludes teachers from participation in the threat assessment team so as not to interfere with their primary role as instructors, one could argue for their inclusion. When students do communicate their plans to others, teachers represent the second mostly likely recipient of that information after peers (Department of Justice, 2002). Faculty members, therefore, possess vital information necessary for the success of the threat assessment team. The proper creation and maintenance of a threat assessment team, in conjunction with an updated crisis management plan based on sound threat assessment techniques, affords an institution the best opportunity to succeed at mitigating on-campus gun violence.

Unfortunately, the battle continues for administrators and school districts across the country. While 33 states currently require their schools to possess a working crisis management plan, gaps persist within the current standards. Although school gun violence waned following the postColumbine provisions instituted in America's schools-including student-based educational directives addressing violence prevention, anger management, reporting techniques, and crisis resolution-administrators now 
face a previously unrealized challenge. One recent crisis situation, in an area not far from the horrors that occurred at Columbine more than seven years ago, illuminates the need for review of institutional crisis management plans. In Bailey, Colorado-a community located about 40 miles southwest of Denver, Duane Morrison-a 54-yearold man with no apparent connection to rural Platte Canyon High School entered campus during a class change on September 27 th, walked purposefully to a second floor classroom, and took six young girls hostage for more than four hours (Maxwell, October 4, 2006). The ability of the local law enforcement to follow procedures previously outlined in an established crisis management plan resulted in the successful evacuation of all but one student, Emily Keyes, who died of a gun shot wound to the back as she tried to flee Morrison during the SWAT team's rush of the classroom (Woodward, October 1, 2006). The strategy established and followed during this emergency resulted from changes to the crisis management plan instituted after the incident at Columbine High School, a mere 30 miles from Platte Canyon (Maxwell, October 4, 2006). The execution of the response stage of the crisis management plan proceeded as intended, but the incident itself may have occurred due to a lapse in the prevention and mitigation phases of the preparedness plan.

Kenneth Trump, a school safety consultant and author of several books on school crisis management plans, praised Park County for adopting such effective post-Columbine response procedures (Maxwell, October 4, 2006). Rather than waiting to enter the school-the previous law enforcement procedure often criticized as the key that allowed Klebold and Harris to inflict such a high death toll at Columbine-the Park County SWAT team invaded the building immediately in an attempt to isolate and neutralize Mr. Morrison as quickly as possible (Omoike, 2000; Maxwell, October 4, 2006). Once stationed outside the classroom, police officers worked tirelessly with Morrison, attempting to reach a peaceful conclusion to the hostage situation until he refused to negotiate any further, at which time Sheriff Fred Wegener gave the order to take him out (Woodward, October 10, 2006). Investigators discerned from video surveillance that Morrison visited Platte Canyon High School no less than three times that morning, waiting in his car for over an hour before finally entering the school at around eleven in the morning (Boniface, October 11, 2006). Students reported that Morrison blended right in between classes, with many students claiming they thought he was a parent (Harrison, October 11, 2006). The ease with which Morrison accessed Platte Canyon presents a shortcoming in the district's current threat assessment and prevention plan.

Maury Nation, an assistant professor of human and organizational development at Vanderbilt University, identified this recent shooting at Platte Canyon High School as a departure from previous school violence (Krishnamoorthi, October 5, 2006). Nation stated, “I think we're looking at a new class of violence at school. It's hard to make a connection between what happened at Columbine and what's happening now because they are so different." 
(Krishnamoorthi, October 5, 2006). As asserted by Nation, Platte Canyon represents a new threat to schools, a threat that must be placed within working crisis management plans. Having learned from the mistake of waiting after Jonesboro and Paducah in the early 1990s, officials in Bailey have already begun the process of reviewing their crisis management plans (Cardona, October 3, 2006). Following the recommendations of the FBI's threat assessment procedure, Superintendent Jim Walpole stated that staff, parents, community members, and law enforcement agencies would be integrally involved in the review of the safety and crisis plans "to determine if more can be done to keep their campuses safe" (Cardona, October 3, 2006). While safety plans before the shooting underwent monthly and quarterly reviews by both school administrators and law enforcement, measures to prevent a hostage crisis committed by an outside assailant had not been addressed (Cardona, October 3, 2006). New security measures instituted immediately after the attack-including more frequent patrols through parking lots and the creation of a single entrance into the school manned by a police officer-represent the administration's understanding that, though this event may be called random, an institution can ill afford to not prepare for every possible threat, as suggested and facilitated by Burnett's threat matrix (Burnett, 1998; Harrison, October 11, 2006). The response of Platte Canyon High School to this new danger reflects similar measures taken by institutions after the devastation of Columbine. Hopefully, other schools will follow suit so as to prevent the loss of one more life due to this newly identified threat.

In the wake of student-committed gun violence during the 1990s, school administrators and federal agencies began a reflective investigation into mistakes made in prevention of crises across the nation. Steeped heavily in the public relations research of crisis communication and management planning, institutions began to implement emergency preparedness plans focused on proactive involvement in students' lives, identifying threat assessment rather than profiling as the main tool in this war on school shootings. The document released by the Department of Education, in conjunction with the United States Secret Service and the Department of Justice, in 2003, drew its background information from previous research in the business world. Recognizing the importance of environmental scanning, crisis communication as a means to mitigate harm, and the best composition of a crisis management team to alleviate stress, the work of Seeger et al. (2001) greatly influenced the suggested guidelines. Further, Burnett's (1998) "vulnerability audit" informs the FBI's suggested brainstorming session during the preparation phase in which school officials identify as many threats as possible. Finally, Penrose's (2000) claim as to the influence of perception on crisis management colors much of current preparedness initiatives in schools across the country. Crisis management plans exploit the caring orientation of the culture fostered at public schools, empowering and imploring teachers to stay involved with and connected to their students' lives. The alignment of crisis 
management and culture aids emergency plans in their mission to succeed. The threat assessment technique heralded by the FBI represents a comprehensive and informed means to deal with emergencies; it simply requires review to account for new threats. Let the reflection begin.

\section{References}

Boniface, D. (2006), "Timeline of events at Platte Canyon High School released," Channel 9 News, October 11, Retrieved November 10, 2006, from http://www.9news.com.

Brickman, H.K., Jones, S.E. and Groom, S.E. (2004), "Evolving school-crisis management since 9/11 [Electronic version]," The Education Digest, 69, 9, pp. 29-35. Retrieved November 10, 2006, from http://proquest.umi.com/pqdlink? did $=630195341 \&$ Fmt $=7$ \&clientld $=2335 \&$ RQT $=$ 309\&V Name=PQD.

Burnett, J.J. (1998), "A strategic approach to managing crises," Public Relations Review, 24, 4, pp. 475-488.

Cardona, F. (2006), "School safety review underway," Denver Post, October 3, Retrieved October 3, 2006, from http://www.denverpost. com.

Clabaugh, G.K. and Clabaugh, A.A. (2005), "Bad apples or sour pickles? Fundamental attribution error and the Columbine Massacre," Educational Horizons, 96, 4, pp. 81-86.

Cornell, D. and Williams, F. (2006), "Student threat assessment as a strategy to reduce school violence", in S. Jimerson and M. Furlong (eds.), Handbook of School Violence and School Safety, Lawrence Erlbaum Associates, Mahwah, NJ, pp. 587-601.

Harrison, S. (2006), "CBI updates Platte County fatal shooting probe," News Channel 13, October 11, Retrieved November 10, 2006, from http://www.krdotv.com.
Krishnamoorthi, H. (2006), "NEWS: Victims of Monday shooting laid to rest in Pennsylvania," Inside Vandy, October 5, Retrieved November 10, 2006, from http://www.insidevandy.com/ drupal/node/1092.

Maxwell, L.A. (2006), "Hostage-taking seen as difficult to prevent," Education Week, October 4, Retrieved October 4, 2006, from http://www. edweek.org.

Mohandie, K. (2002), School Violence Threat Management: A Practical Guide for Educators, Law Enforcement, and Mental Health Professionals, Specialized Training Services, San Diego.

Omoike, I.I. (2000), The Columbine High School Massacre: An Investigatory Analysis, Baton Rouge, Author.

Penrose, J.M. (2000), "The role of perception in crisis planning," Public Relations Review, 26, 2, pp. 155-171.

Seeger, M.W., Sellnow, T.L. and Ulmer, R.R. (2001), "Public relations and crisis communication: organizing and chaos", in R. Heath (ed.), Handbook of Public Relations, Sage Publications: Thousand Oaks, CA, pp. 155-165.

Trump, K.S. (ed.) (1999), Stopping School Violence: An Essential Guide, Apsen, Gaithersburg.

U.S. Department of Education (1999), 1998 Annual Report on School Safety, U.S. Department of Justice, Washington, DC.

U.S. Department of Justice (2002), Preventing School Shootings: A Summary of a U.S. Secret Service Safe School Initiative Report Report No. NCJ-190633, National Institute of Justice, Washington, DC (ERIC Document Reproduction Service No. ED465925).

Vossekuil, B., Fein, R.A., Reddy, M., Borum, R. and Modzeleski, W. (2002), The Final Report and Findings of the "Safe School Initiative": Implications for the Prevention of School Attacks in the United States, Department of Education, Washington, DC; United States Secret Service, Washington, DC (ERIC Document Reproduction Service No. ED466024).

Woodward, P. (2006), "Why the decision was made at Platte Canyon High School," Channel 9 News, October 1, Retrieved November 10, 2006, from http://www.9news.com. 